\title{
Hyperglycemia decreases mitochondrial function: The regulatory role of mitochondrial biogenesis
}

\author{
Carlos M. Palmeira ${ }^{\mathrm{a}, *}$, Anabela P. Rolo ${ }^{\mathrm{a}}$, Jessica Berthiaume ${ }^{\mathrm{b}}$, \\ James A. Bjork ${ }^{\mathrm{b}}$, Kendall B. Wallace ${ }^{\mathrm{b}}$ \\ ${ }^{a}$ Center for Neurosciences and Cell Biology of Coimbra, Department of Zoology, University of Coimbra, 3004-517 Coimbra, Portugal \\ ${ }^{\mathrm{b}}$ Department of Biochemistry and Molecular Biology, University of Minnesota School of Medicine, Duluth, MN, USA
}

Received 14 May 2007; revised 13 July 2007; accepted 27 July 2007

Available online 7 August 2007

\begin{abstract}
Increased generation of reactive oxygen species (ROS) is implicated in "glucose toxicity" in diabetes. However, little is known about the action of glucose on the expression of transcription factors in hepatocytes, especially those involved in mitochondrial DNA (mtDNA) replication and transcription. Since mitochondrial functional capacity is dynamically regulated, we hypothesized that stressful conditions of hyperglycemia induce adaptations in the transcriptional control of cellular energy metabolism, including inhibition of mitochondrial biogenesis and oxidative metabolism. Cell viability, mitochondrial respiration, ROS generation and oxidized proteins were determined in HepG2 cells cultured in the presence of either $5.5 \mathrm{mM}$ (control) or $30 \mathrm{mM}$ glucose (high glucose) for $48 \mathrm{~h}, 96 \mathrm{~h}$ and 7 days. Additionally, mtDNA abundance, plasminogen activator inhibitor-1 (PAI-1), mitochondrial transcription factor A (TFAM) and nuclear respiratory factor-1 (NRF-1) transcripts were evaluated by real time PCR. High glucose induced a progressive increase in ROS generation and accumulation of oxidized proteins, with no changes in cell viability. Increased expression of PAI-1 was observed as early as $96 \mathrm{~h}$ of exposure to high glucose. After 7 days in hyperglycemia, HepG 2 cells exhibited inhibited uncoupled respiration and decreased MitoTracker Red fluorescence associated with a 25\% decrease in mtDNA and $16 \%$ decrease in TFAM transcripts. These results indicate that glucose may regulate mtDNA copy number by modulating the transcriptional activity of TFAM in response to hyperglycemia-induced ROS production. The decrease of mtDNA content and inhibition of mitochondrial function may be pathogenic hallmarks in the altered metabolic status associated with diabetes.
\end{abstract}

(C) 2007 Elsevier Inc. All rights reserved.

Keywords: Hyperglycemia; Mitochondrial biogenesis; Oxidative stress; Bioenergetics

\section{Introduction}

Diabetes mellitus is a metabolic disorder characterized by hyperglycemia and insufficiency of secretion or receptor insensitivity to endogenous insulin. The number of adults with clinical diagnosis of diabetes has been increasing dramatically worldwide. It has been estimated that the number of adults affected by diabetes in the world will grow from 135 million in 1995 to 300 million in the year 2025 (King et al., 1998). While exogenous insulin and other medications can control many aspects of diabetes, assorted complications affecting the

\footnotetext{
* Corresponding author. Fax: +351 239855789.

E-mail address: palmeira@ci.uc.pt (C.M. Palmeira).
}

vascular system, kidney, and peripheral nerves are common and extremely costly in terms of longevity and quality of life.

It is well established that hyperglycemia elicits an increase in reactive oxygen species (ROS) production, due to increased input of reducing equivalents into the mitochondrial electron transport chain (Nishikawa et al., 2000a; Brownlee, 2001). ROS overproduction is the trigger of the pathways responsible for hyperglycemia-induced cell damage: (1) increased polyol pathway flux; (2) increased advanced glycation end product (AGE) formation; (3) activation of protein kinase $\mathrm{C}$ (PKC) isoforms; and (4) increased hexosamine pathway flux (Nishikawa et al., 2000b; Brownlee, 2001; Robertson, 2004).

Diabetes-associated alterations in mitochondrial phenotype have been widely described (Rolo and Palmeira, 2006). In animal models of diabetes, distinct mitochondrial alterations as a 
function of age have been observed, indicating differential adaptation mechanisms to counteract high glucose levels (Palmeira et al., 1999; Ferreira et al., 1999, 2003). Since mitochondrial number and function require both nuclear and mitochondrial-encoded genes, coordinated mechanisms exist to regulate the two genomes and determine the overall oxidative capacity (Kelly and Scarpulla, 2004). Adaptive responses of mitochondrial function to diabetic stress may reflect changes in mitochondrial gene expression induced by hyperglycemia. Growing evidence indicates that several transcriptional changes in diabetes are associated with impaired mitochondrial function and altered glucose and fatty acid metabolism, characteristics of diabetes mellitus. Reduced expression of oxidative phosphorylation genes has been observed in type 2 diabetes (Mootha et al., 2003), accompanied by decreased expression of peroxisomal proliferators activator receptor $\gamma$ coactivator- $\alpha$ $(\mathrm{PGC}-1 \alpha)$ in prediabetic and diabetic muscle (Patti et al., 2003). PGC- $1 \alpha$ is an integrator of the molecular regulatory circuit involved in the transcriptional control of cellular energy metabolism, including mitochondrial biogenesis, hepatic gluconeogenesis, and fatty acid $\beta$-oxidation (Puigserver and Spiegelman, 2003). Recent work by Yu and collaborators has shown that exposure to high glucose conditions leads to dynamic changes in mitochondrial morphology due to prolonged ROS overproduction (Yu et al., 2006). However, the relationship between ROS production and mitochondrial biogenesis is still unclear.

Based on the indication of modulation of gene expression and alteration of mitochondrial function by hyperglycemia, we hypothesize that hyperglycemia-induced increased ROS production is the trigger for decreased mitochondrial biogenesis. We demonstrated that prolonged hyperglycemia-induced ROS overproduction causes a decrease in mitochondrial copy number in HepG2 cells. We also found that this decrease in mitochondrial biogenesis is coincident to a decrease in TFAM transcripts and results in a loss of respiratory efficiency. Liver being the primary organ involved in blood glucose metabolism, decreased mitochondrial biogenesis and subsequent impairment of oxidative metabolism will establish a vicious cycle of metabolic alterations implicated in diabetes pathogenesis.

\section{Materials and methods}

Cell culture. HepG2/C3A cells obtained from American Type Culture Collection (ATCC, Rockville, MD) were cultured in Eagle's minimum essential medium (MEM) (with $2 \mathrm{mM}$ L-glutamine and Earl's BSS adjusted to contain $1.5 \mathrm{~g} / 1$ sodium bicarbonate, $0.1 \mathrm{mM}$ nonessential amino acids, and $1 \mathrm{mM}$ sodium pyruvate (Sigma, St. Louis, MO)), supplemented with $10 \%$ fetal bovine serum. Cells were plated on $25-$ or $75-\mathrm{cm}^{2}$ tissue culture flasks and grown in a $5 \% \mathrm{CO}_{2}$ incubator at $37{ }^{\circ} \mathrm{C}$ with saturating humidity and growth media changes every 2 days. At $80-90 \%$ confluence, cells were passaged by detachment with $0.05 \%$ trypsin and $0.5 \mathrm{mM}$ EDTA (Invitrogen, Carlsbad, CA) and re-seeded into new flasks. Harvesting of cells was accomplished by trypsinization or by removing the media and scraping in a small volume of assay dependent specific buffer. For hyperglycemic exposure of the cells for $48 \mathrm{~h}, 96 \mathrm{~h}$ or 7 days, culture media was supplemented with $30 \mathrm{mM}$ glucose.

Cell viability. Viability or cell killing was evaluated by using the fluorescent markers Ethidium homodimer-1 (EtHD-1) and calcein-AM (Molecular Probes, Eugene, OR). EtHD-1 is excluded from cells with intact membranes but readily enters dead cells and intercalates DNA, thereby producing a bright red fluorescence in dead cells (ex/em $\sim 495 \mathrm{~nm} / \sim 635 \mathrm{~nm}$ ). C-AM freely diffuses into cells and is cleaved by intracellular esterases to the fluorescent isoform, which is polarized and trapped in the cell, producing a bright green fluorescence in live cells (ex/em $\sim 495 \mathrm{~nm} / \sim 515 \mathrm{~nm}$ ). Cells were harvested by trypsinization and washed twice with PBS. Cells were resuspended in the working solution of calcein-AM $(2 \mu \mathrm{M})$ and EtHD-1 $(4 \mu \mathrm{M})$ and incubated for $30 \mathrm{~min}$ at $37^{\circ} \mathrm{C}$. The cells were then analyzed with a FACSCalibur flow cytometer (Becton Dickinson, San Jose, CA, US) and CELLQuest software. Approximately $10^{5}$ cells were analyzed for each time point and condition. Viability or cell killing is calculated as a ratio of EtHD-1 and calcein-AM events (Rolo et al., 2004).

In cyto mitochondrial ROS generation. ROS were determined fluorometrically using a Labsystems type 374 plate-reader fluorometer. The formation of the oxidized derivative of 5-(and 6-)-chloromethyl-2', $7^{\prime}$-dichlorodihydrofluorescein $\left(\mathrm{CM}-\mathrm{H}_{2} \mathrm{DCF}\right)$ was monitored fluorometrically at an excitation wavelength $485 \mathrm{~nm}$ and an emission wavelength $538 \mathrm{~nm}$ (Zhou et al., 2001). Briefly, cells were collected by trypsinization and centrifugation, and resuspended at $1 \times 10^{6}$ cells per $\mathrm{ml}$ in culture media. Cells were loaded with $50 \mu \mathrm{M} \mathrm{CM}-\mathrm{H}_{2}$ DCFDA (Molecular Probes), prepared in DMSO, for $15 \mathrm{~min}$ at $37^{\circ} \mathrm{C}$ and $200 \mu \mathrm{l}$ of the cell suspension $\left(10^{5}\right.$ cells $)$ were loaded into a 96 -well plate. The fluorescence was monitored for $30 \mathrm{~min}$ to calculate the rate of ROS formation.

Oxidized proteins detection. Protein carbonyl groups were immunodetected with OxyBlot Protein Oxidation Detection Kit (Chemicon International, Temecula, CA), according to manufacturer's suggestions. Briefly, cells were collected by trypsinization and centrifugation, resuspended in $200 \mu \mathrm{l}$ of ice-cold PBS and homogenized by syringe and needle. $20 \mu \mathrm{g}$ of protein were denatured with an equal volume of SDS (final concentration of $6 \%$ SDS) and derivatized with 2 volumes of 2,4-dinitrophenylhydrazine (DNPH) solution. After incubation at room temperature for $15 \mathrm{~min}$, the reaction was stopped by addition of the neutralization solution. The derivatized protein samples were separated by standard SDS PAGE using precast gels. Proteins were then transferred to a nitrocellulose membrane for $90 \mathrm{~min}$ at $100 \mathrm{~V}$ in transfer buffer (25 mM Tris, $190 \mathrm{mM}$ glycine, 20\% methanol) containing $0.01 \%$ SDS. The loading and transfer of equal amounts of protein was confirmed by staining the nitrocellulose membrane with Ponceau S (data not shown). Non-specific sites on the membrane were blocked in a $1 \%$ casein solution of Tris-buffered saline with $0.1 \%$ Tween 20. Membranes were blotted with rabbit anti-DNP (1:150, 90451 from Chemicon International, CA). A horseradish peroxidase-conjugated secondary antibody (goat anti-rabbit 90452, 1:300, Chemicon International, CA) was used for the detection of immunoblotted proteins according to manufacturer's recommendations (Pierce, IL). Chemiluminescence was detected on film.

Measurement of protein carbonyl by spectrophotometry. Protein carbonyl content was measured by using 2,4-dinitrophenyl-hydrazine (DNPH) (Levine et al., 1994). Cells were collected by trypsinization and centrifugation, resuspended in $200 \mu \mathrm{l}$ of ice-cold PBS and homogenized by syringe and needle. $500 \mu 1$ ice-cold trichloroacetic acid $(20 \% \mathrm{w} / \mathrm{v})$ were added to $250 \mu \mathrm{g}$ of sample and allowed to stand for $15 \mathrm{~min}$ at $4{ }^{\circ} \mathrm{C}$. The precipitated protein was collected by centrifugation at $6500 \times \mathrm{g}$ for $10 \mathrm{~min}$, and the supernatant was discarded. The pellet was fully resuspended in $500 \mu 1$ of $0.1 \mathrm{M} \mathrm{NaOH}$. $500 \mu 1$ of $10 \mathrm{mM} \mathrm{DNPH}$ dissolved in $2 \mathrm{M} \mathrm{HCl}$ was added to the sample tube. In a parallel, a blank was prepared by addition of $500 \mu \mathrm{l}$ of $2 \mathrm{M} \mathrm{HCl}$ containing no DNPH to the protein sample. After incubation at room temperature, in the dark, for $30 \mathrm{~min} 500 \mu \mathrm{l}$ of trichloroacetic acid $(20 \% \mathrm{w} / \mathrm{v})$ were added. The precipitated protein was collected by centrifugation at $6500 \times \mathrm{g}$ for $10 \mathrm{~min}$, and the supernatant was discarded. The pellet was washed three times with $1 \mathrm{ml}$ of a 1:1 (v/v) mixture of ethanol and ethyl acetate and centrifuged at $6500 \times \mathrm{g}$ for $5 \mathrm{~min}$ to remove free reagent. The final precipitated protein was redissolved in $200 \mu 1$ of $6 \mathrm{M}$ guanidine hydrochloride solution. The amount of protein dinitrophenylhydrozone derivative was quantified by measuring the absorbance at $365 \mathrm{~nm}$ and converted to nmol of hydrazone by using a molar absorption coefficient of $22,000 \mathrm{M}^{-1} \mathrm{~cm}^{-1}$. Carbonyl content was expressed as nmol of DNPH incorporated per milligram of protein. 
Oxygen consumption rates in digitonin-permeabilized cells. Oxygen consumption rates were measured in permeabilized cells using a Clark-type $\mathrm{O}_{2}$ electrode. Cells were collected by trypsinization and centrifugation, and resuspended at $5 \times 10^{6}$ cells per $\mathrm{ml}$ in $1 \mathrm{ml}$ of buffer A $(250 \mathrm{mM}$ sucrose, $10 \mathrm{mM} \mathrm{MgCl} 2,20 \mathrm{mM}$ HEPES (pH 7.1)). $1 \mathrm{ml}$ of buffer A containing $50 \mu \mathrm{g}$ digitonin was then added to the cell suspension. The suspension was placed in a water bath at $37{ }^{\circ} \mathrm{C}$ with agitation for 3 min and then diluted with $8 \mathrm{ml}$ of buffer A. Cells were then collected by centrifugation and resuspended in $700 \mu \mathrm{l}$ of respiration buffer $(250 \mathrm{mM}$ sucrose, $10 \mathrm{mM} \mathrm{MgCl} 2,2 \mathrm{mM}$ $\mathrm{KH}_{2} \mathrm{PO}_{4}, 20 \mathrm{mM}$ HEPES (pH 7.1)). Each sample was transferred into a water-jacketed chamber containing a magnetic bar and connected to a circulating water bath at $28{ }^{\circ} \mathrm{C}$ and a YS model 5300 biological oxygen monitor (Yellow Springs Instruments). After equilibration of the cell suspension, $10 \mathrm{mM}$ glutamate/malate were added to the chamber, following an additional equilibration ADP $1 \mathrm{mM}$ was added. Uncoupled respiration was evaluated in cells resuspended in respiration media supplemented with glutamate/malate by adding DNP $10 \mu \mathrm{M}$ to stimulate oxygen consumption; after allowing adequate time for accurate slope measurement, $2 \mathrm{mM} \mathrm{KCN}$ was added (Hofhaus et al., 1996).

Fluorescence microscopy of cultured cells. Cells were collected by trypsinization and centrifugation, washed with PBS, seeded at approximately $30 \%$ confluence in 6-well plates on glass cover slips, incubated overnight and then stained with Mitotracker Red (Molecular Probes) for $15 \mathrm{~min}$. Cells were then rinsed with PBS and fresh media was added. Cells were visualized using a Nikon Eclipse TE300 inverted epifluorescence microscope.

Quantitative real-time PCR for measurement of mtDNA copies/cell. DNA was extracted using phenol/chloroform precipitation methods and stored in water at $-80{ }^{\circ} \mathrm{C}$ until analysis (Strauss, 1998). Purity and concentration of DNA recovered were determined with a NanoDrop spectrophotometer. To assess mtDNA content per cell, we measured the number of copies of wellconserved single-copy genes (Berthiaume and Wallace, 2002). Primers were designed based on sequence information in GenBank using OLIGO 5.0. Pyruvate kinase (forward primer, caaggcccagagaagtatgatg; reverse primer, gtggcagggaaggtctaggtag; $345 \mathrm{bp}$ product) was used as a marker for nuclear DNA, while cytochrome $b$ (forward primer, atgaaacttcggctcactcct; reverse

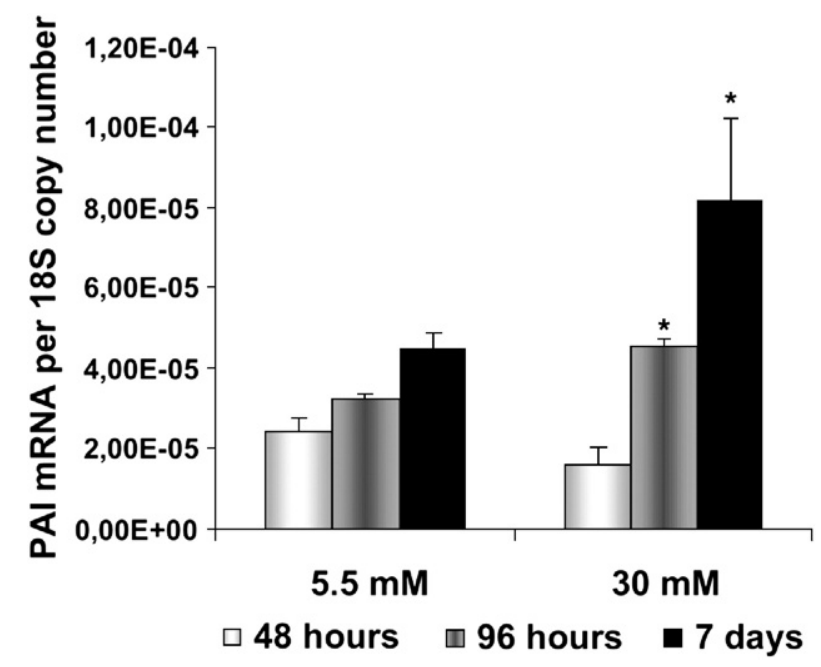

Fig. 1. Exposure of HepG2 cells to hyperglycemia $(30 \mathrm{mM})$ induce an increase on the levels of PAI mRNA transcript. Cells were cultured in $5.5 \mathrm{mM}$ or $30 \mathrm{mM}$ glucose for 48 h, $96 \mathrm{~h}$ and 7 days. PAI expression was quantified by real-time PCR from a generated standard curve and normalized by calculating the ratio of PAI gene copy number to $18 \mathrm{~S}$ rRNA copy number. Bars represent the mean \pm S.E.M. for three different cell cultures. No statistically significant difference was observed between HepG2 cells cultured in $5.5 \mathrm{mM}$ and $30 \mathrm{mM}$ glucose for $48 \mathrm{~h}$. Asterisk $\left(^{*}\right)$ indicates statistical difference of the hyperglycemic condition ( $96 \mathrm{~h}$ and 7 days) when compared with the respective normoglycemic $(5.5 \mathrm{mM})$ control group $(p<0.05)$.

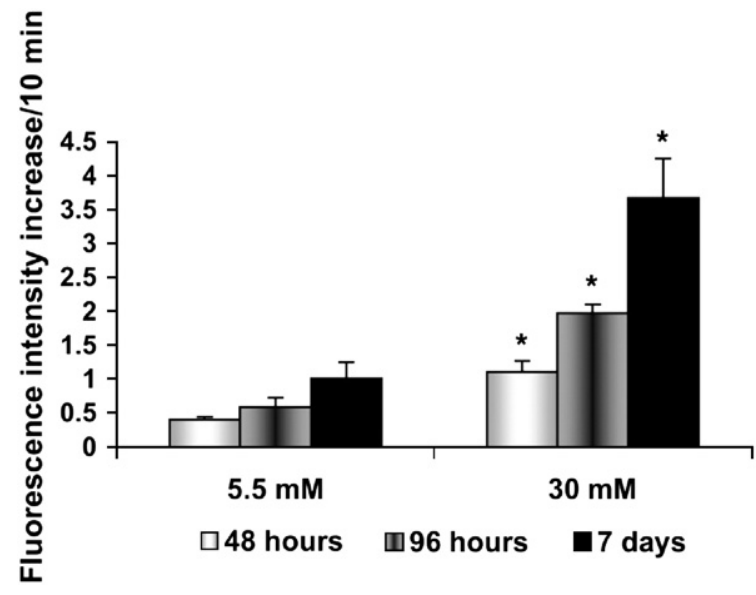

Fig. 2. Exposure of HepG2 cells to hyperglycemia $(30 \mathrm{mM})$ induce an increase in ROS formation. Cells were cultured in $5.5 \mathrm{mM}$ or $30 \mathrm{mM}$ glucose for $48 \mathrm{~h}, 96 \mathrm{~h}$ and 7 days. ROS were estimated fluorometrically using the probe CMH2DCFDA, and are expressed as fluorescent intensity increase per $10^{5}$ cells per $10 \mathrm{~min}$. Bars represent the mean \pm S.E.M. for three different cell cultures. All the bars at $30 \mathrm{mM}$ glucose are statistically different when compared with the corresponding normoglycemic $(5.5 \mathrm{mM})$ control group $(p<0.05)$.

primer, tgtatgggatggcggatagta; $377 \mathrm{bp}$ product) was used as a marker for mtDNA (IDT, Coralvill, IA). Real-time PCR reactions were prepared with LightCycler ${ }^{\circledR}$ FastStart DNA Master SYBR Green 1 reagents according to kit suggestions with $0.5 \mu \mathrm{M}$ concentrations of each primer and $2 \mathrm{mM} \mathrm{MgCl}_{2}$, in a LightCycler 1.5 ${ }^{\circledR}$ (Roche Diagnostics, Indianapolis, IN). Samples were diluted to $5 \mathrm{ng} / \mu 1$ and then $5 \mathrm{ng}$ of sample was used to amplify the nuclear or the mitochondrial gene products. Quantification of mtDNA was accomplished by calculating the ratio of a mitochondrially encoded gene (cytochrome $b$ ) to a nuclear encoded gene (pyruvate kinase) and expressing it as mtDNA copy number per cell. To assess the specificity of the amplified PCR products, a melting curve analysis was performed and reaction end products subjected to gel electrophoresis. Copy numbers for each gene were calculated based on standard curves. Standards were generated by PCR of DNA with specific primers for each gene using Qiagen HotStartTaq Master Mix (Qiagen, Valencia, CA). PCR was conducted in a Perkin-Elmer thermocycler. Agarose gel electrophoresis was performed to verify products. Products were then purified using a QIAquick PCR purification kit according to manufacturer's instructions (Qiagen) and quantitated by measuring absorbance at $260 \mathrm{~nm}$. DNA copy number was calculated using the resulting concentration of DNA and the following equation: $\mathrm{MW}=($ product length $\times 607.4)+157.9$ (Ambion Inc., Austin, TX).

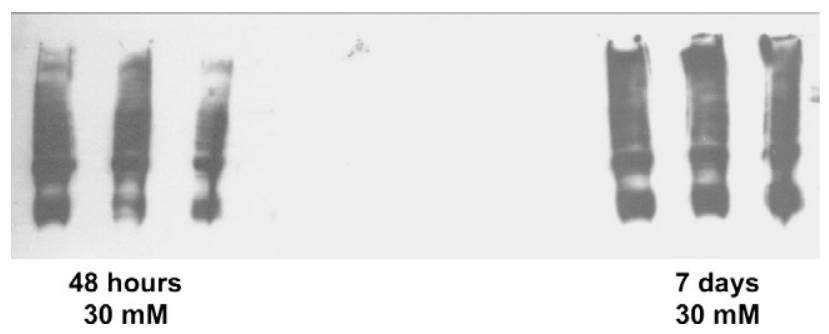

Fig. 3. High glucose-induced protein oxidation in HepG2 cells. Western blot analysis of oxidative damage protein carbonylation was performed by using an antibody against carbonyl groups as a marker for protein oxidative damage. The loading and transfer of equal amounts of protein was confirmed by staining the nitrocellulose membrane with Ponceau S (data not shown). The figure is representative of results obtained with three different cultures exposed to hyperglycemia for $48 \mathrm{~h}$ and 7 days. 


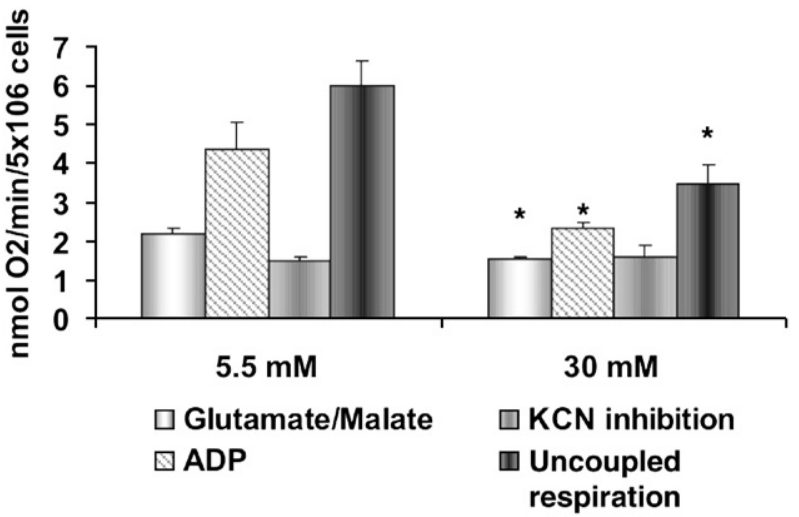

Fig. 4. Prolonged exposure to hyperglycemia $(30 \mathrm{mM})$ induce a decrease in mitochondrial oxygen consumption rates in digitonin-permeabilized HepG2 cells. Cells were cultured in $5.5 \mathrm{mM}$ or $30 \mathrm{mM}$ glucose for and 7 days. After permeabilization with digitonin, oxygen consumption induced by glutamate/ malate $(10 \mathrm{mM})$, ADP $(1 \mathrm{mM}), \mathrm{KCN}(2 \mathrm{mM})$ was evaluated. Uncoupled respiration or DNP-stimulated mitochondrial oxygen consumption $(10 \mu \mathrm{M})$ was also evaluated. Bars represent the means \pm S.E.M. for three different experiments. No statistically significant difference was observed in KCN inhibition of oxygen consumption between HepG2 cells cultured in $5.5 \mathrm{mM}$ and $30 \mathrm{mM}$ glucose. Asterisks $(*)$ indicate statistically significant difference of oxygen consumption induced by glutamate/malate, ADP or DNP in HepG2 cells cultured in $30 \mathrm{mM}$ glucose when compared, respectively, with glutamate/malate, ADP or DNP oxygen consumption in HepG2 cells cultured in $5.5 \mathrm{mM}$ glucose $(p<0.05)$.

Quantitative real-time PCR of TFAM, NRF-1 and PAI-1 mRNA. Total RNA was extracted from cells using the RNeasy kit (Qiagen) and processed according to manufacturer's suggestions. Reverse transcription PCR was performed with the Omniscript RT Kit (Qiagen) using $1.0 \mu \mathrm{g}$ of total RNA. Each reaction was multiplexed, using the lower primer for both the housekeeping gene, 18S rRNA, and the genes of interest to allow for normalization. Primers were designed based on sequence information in GenBank using OLIGO 5.0: TFAM (forward primer, catctgtcttggcaagttgtcc; reverse primer, ccactecgecctataagcatc; 194 bp product), NRF-1 (forward primer, gatggcactgtctcacttatcc; reverse primer, ctgatgcttgegtcgtct; $193 \mathrm{bp}$ product), PAI-1 (forward primer, tagagaacctgggaatgaccga; reverse primer, tgcgggctgagactatgaca; $171 \mathrm{bp}$ product) and $18 \mathrm{~S}$ (forward primer, cgtattgcgecgctagaggt; reverse primer, ggtgaggtttccegtgttgag; 327 bp product). Real-time PCR was performed in a Lightcycler@ using the SYBR Green Master Mix Kit, as described in the previous section. Amplification of the 18S and gene of interest were performed independently using the same reverse transcription reaction.
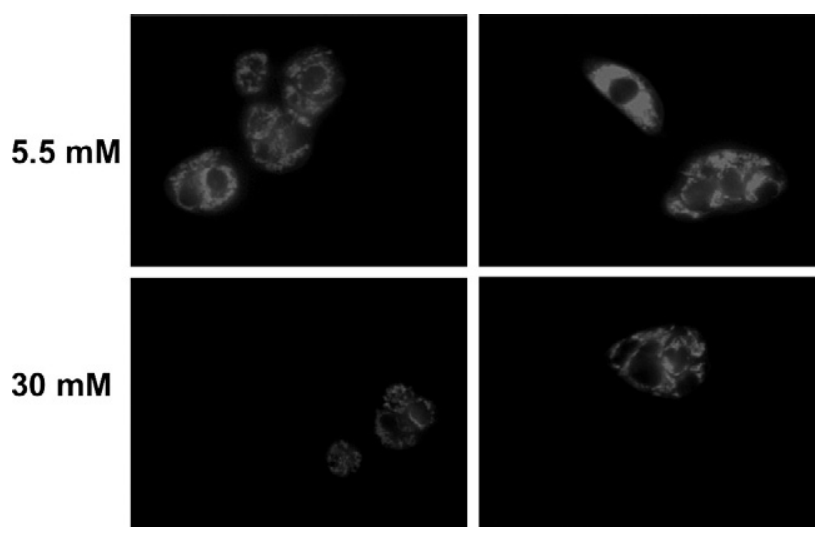

Fig. 5. Prolonged exposure of HepG2 cells to hyperglycemia $(30 \mathrm{mM})$ induce a decrease in MitoTracker Red staining. Fluorescence microscopy of HepG2 cells cultured for 7 days in $5.5 \mathrm{mM}$ (upper panel) or $30 \mathrm{mM}$ glucose (lower panel), stained with MitoTracker Red.

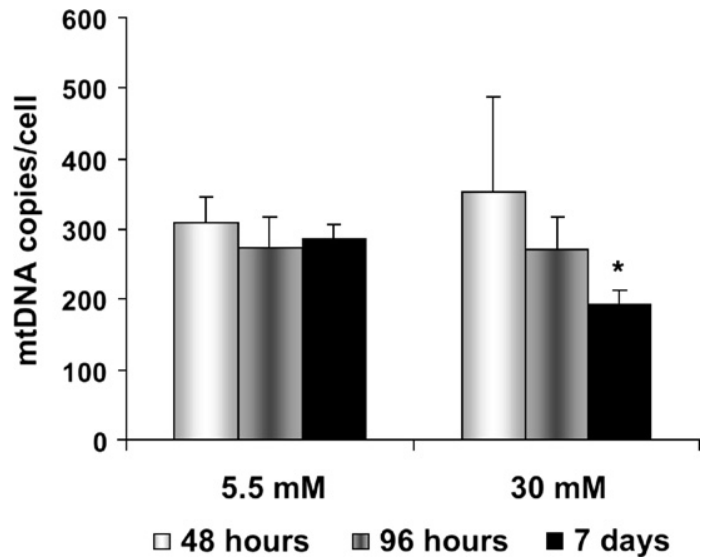

Fig. 6. Prolonged exposure of HepG2 cells to hyperglycemia ( $30 \mathrm{mM})$ induce a decrease on mtDNA copy number per cell. Cells were cultured in $5.5 \mathrm{mM}$ or $30 \mathrm{mM}$ glucose for $48 \mathrm{~h}, 96 \mathrm{~h}$ and 7 days. mtDNA was quantified by real-time PCR by calculating the ratio of mitochondrial gene copy (cytochrome $b$ ) number to nuclear gene (pyruvate kinase) copy number and expressing it as the mtDNA copy number per cell. Copy numbers for each gene were calculated based on standard curves. Bars represent the mean \pm S.E.M. for three different cell cultures. No statistically significant difference was observed in mtDNA copy number between HepG2 cells cultured in $5.5 \mathrm{mM}$ and $30 \mathrm{mM}$ glucose for 48 and $96 \mathrm{~h}$. Asterisk $(*)$ indicates statistical difference between cells cultured in $30 \mathrm{mM}$ and $5.5 \mathrm{mM}$ glucose for 7 days $(p<0.05)$.

Protein determination. Protein concentration was determined using the Bradford protein assay with BSA as the protein standard (Bradford, 1976).

Statistical analysis. Data from three different experiments are presented as the mean \pm S.E.M. Statistical significance between the different assays was made using the two-way analysis of variance followed by the Newman-Keuls posttest. $p$ values $<0.05$ denoted the presence of a statistically significant difference.

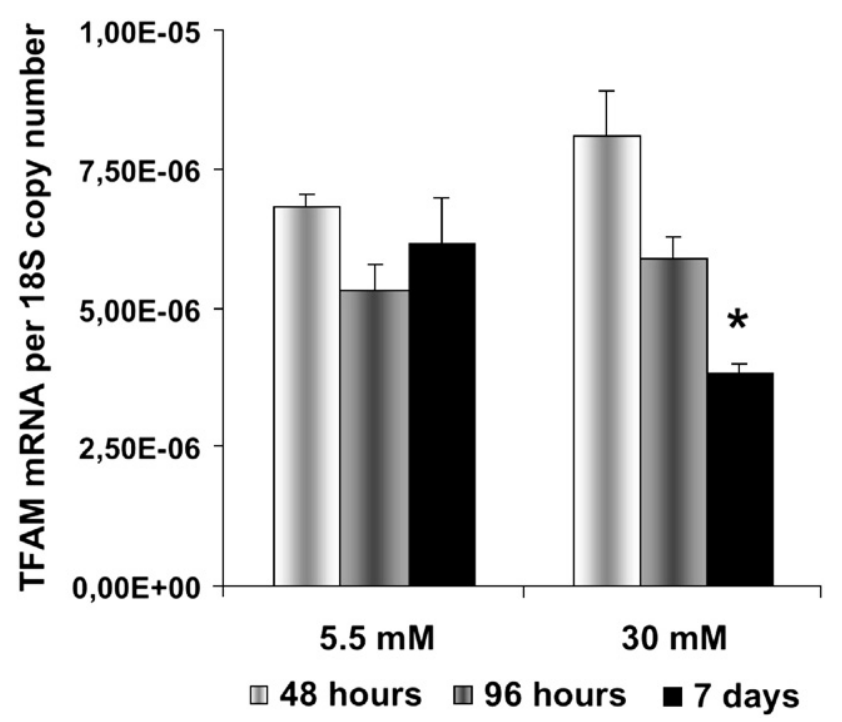

Fig. 7. Prolonged exposure of HepG2 cells to hyperglycemia ( $30 \mathrm{mM})$ induce a decrease on TFAM mRNA transcript. Cells were cultured in $5.5 \mathrm{mM}$ or $30 \mathrm{mM}$ glucose for $48 \mathrm{~h}, 96 \mathrm{~h}$ and 7 days. TFAM expression was quantified by real-time PCR from a generated standard curve and normalized by calculating the ratio of TFAM gene copy number to $18 \mathrm{~S}$ rRNA copy number. Bars represent the mean \pm S.E.M. for three different cell cultures. No statistically significant difference was observed between HepG2 cells cultured in $5.5 \mathrm{mM}$ and $30 \mathrm{mM}$ glucose for 48 and $96 \mathrm{~h}$. Asterisk $(*)$ indicates statistical difference between cells cultured in $30 \mathrm{mM}$ and $5.5 \mathrm{mM}$ glucose for 7 days $(p<0.05)$. 


\section{Results}

Hyperglycemia induces an increase in PAI-1 expression without changes in cell viability

We examined cell viability in HepG2 cells exposed to hyperglycemic conditions ( $30 \mathrm{mM}$ glucose) for $48 \mathrm{~h}, 96 \mathrm{~h}$ and 7 days. No differences were observed in ethidium homodimer-1 and calcein-AM fluorescence when compared with cells cultured in $5.5 \mathrm{mM}$ glucose (data not shown). All cell cultures were greater than $85 \%$ viable with all treatments and at all time points. To confirm that extended exposure of HepG2 cells to high glucose conditions was mimicking untreated diabetic conditions, PAI-1 expression was evaluated. As shown in Fig. 1, PAI-1 expression increased over time, reaching $60 \%$ increase at 7 days of exposure to hyperglycemia, indicating the possible shunt of glucose into the hexosamine pathway, which plays a modulatory role in PAI-1 expression (Brownlee, 2001; Gabriely et al., 2002; Goldberg et al., 2002).

Hyperglycemia stimulates ROS generation that coincides with accumulation of protein oxidation products

To determine the dynamics of ROS generation in HepG2 cells exposed to high glucose, we evaluated intracellular ROS production with the fluorescent probe $\mathrm{CM}-\mathrm{H}_{2} \mathrm{DCF}$. Time course experiments revealed that ROS increased at $48 \mathrm{~h}$, with an increase of 3.6 times in ROS generation after 7 days of exposure to high glucose as compared to control (Fig. 2). Immunodetection of carbonyl groups revealed protein oxidation at $48 \mathrm{~h}$, reaching a maximum after 7 days of exposure to

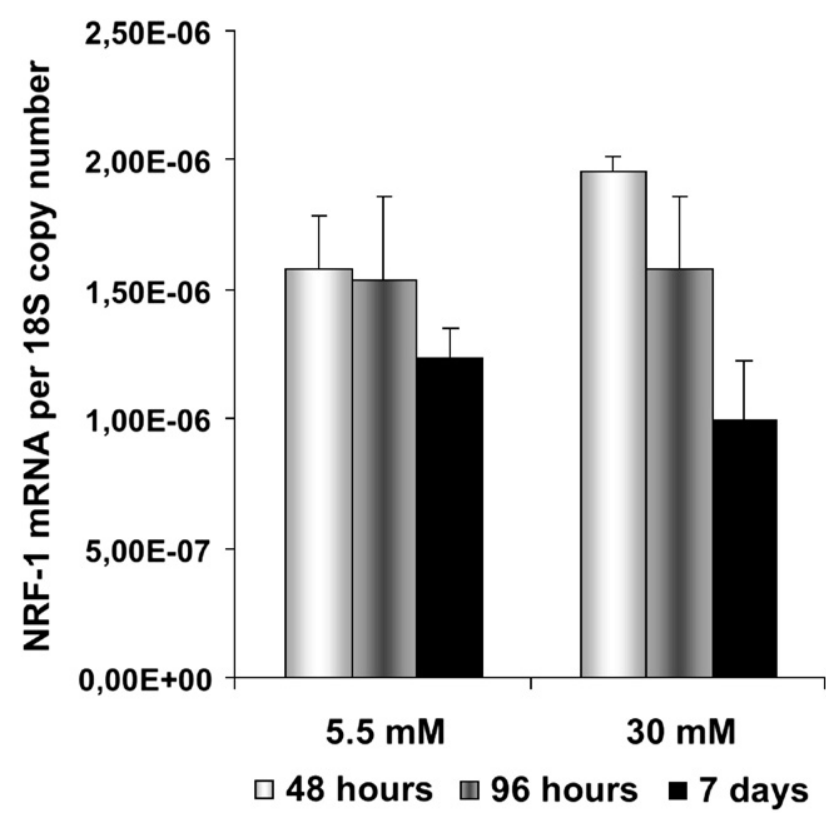

Fig. 8. Effect of high glucose exposure $(30 \mathrm{mM})$ on the levels of NRF-1 mRNA transcript in HepG2 cells. Cells were cultured in $5.5 \mathrm{mM}$ or $30 \mathrm{mM}$ glucose for 48 h, 96 h and 7 days. NRF-1 expression was quantified by real-time PCR from a generated standard curve and normalized by calculating the ratio of NRF-1 gene copy number to $18 \mathrm{~S}$ rRNA copy number. Bars represent the mean \pm S.E.M. for three different cell cultures. No statistically significant difference was observed. high glucose consistent with the ROS increase during hyperglycemia (Fig. 3). The increase in protein carbonyl content in HepG2 cells exposed to hyperglycemia was further confirmed by spectrophotometric assay. Protein carbonyl content was $2.56 \pm 0.11$ and $4.37 \pm 0.37 \mathrm{nmol} / \mathrm{mg}$ protein in cells exposed to hyperglycemia for $48 \mathrm{~h}$ and 7 days, respectively.

Hyperglycemia induces a decrease in mitochondrial respiratory rates and in MitoTracker Red fluorescence

To elucidate whether increased ROS generation was a cause or a consequence of mitochondrial respiratory capacity, we measured oxygen consumption in HepG2 cells under normal and hyperglycemic conditions. No differences were observed at $96 \mathrm{~h}$ (data not shown). Uncoupled respiration (oxygen consumption induced by the protonophore DNP, which makes mitochondrial inner membrane permeable to protons) was inhibited by $40 \%$ in digitonin-permeabilized HepG2 cells cultured for 7 days in $30 \mathrm{mM}$ glucose (Fig. 4). Exposure to high glucose for 7 days induced a decrease in MitoTracker Red fluorescence (Fig. 5), suggesting a decrease in mitochondrial membrane potential or a decrease in the number of mitochondrial structures.

\section{Hyperglycemia induces a decrease in mitochondrial biogenesis}

To address if the loss of respiratory efficiency was due to a loss of mitochondrial transcripts, mRNA levels of TFAM, NRF1 and mtDNA copy number were quantified by real-time PCR. Exposure to high glucose for 7 days induced a $25 \%$ decrease in mtDNA copy number at 7 days (Fig. 6). Concomitantly and as shown in Fig. 7, TFAM transcripts, a direct regulator of mtDNA replication/transcription and a stimuli for the regulation of mitochondrial biogenesis and function (Wu et al., 1999) were decreased $16 \%$ upon 7 days in hyperglycemic conditions. No statistically significant difference was observed for NRF-1 transcripts (Fig. 8).

\section{Discussion}

Our data demonstrate that long-term exposure of HepG2 cells to high glucose conditions leads to loss of respiratory capacity and decreased mitochondrial biogenesis, the two of which may be causally related.

ROS production via the mitochondrial respiratory chain has been shown to be the causal link between high glucose and the main pathways responsible for hyperglycemic damage. The prevailing hypothesis is that hyperglycemia-induced increase in electron transfer donors (NADH and $\mathrm{FADH}_{2}$ ) increases electron flux through the mitochondrial electron transport chain. Consequently, there is an increase of the ATP/ADP ratio and hyperpolarization of the mitochondrial membrane potential. This high electrochemical potential generated by the proton gradient leads to partial inhibition of the electron transport in complex III, resulting in an accumulation of reduced quinone. In turn, this drives partial reduction of $\mathrm{O}_{2}$ to 
generate the free radical anion superoxide (Nishikawa et al., 2000a,b; Brownlee, 2001). It is this accelerated reduction of coenzyme Q and generation of ROS that is believed to be the fundamental source for oxidative injury and mitochondrial dysfunction that plays a critical role in diabetes-related metabolic disorders and tissue histopathology. In this study, we first confirmed that hyperglycemia-induced ROS overproduction is associated with the induction of factors responsible for diabetic complications. Coincident with the increase in ROS generation, there was an accumulation of oxidized proteins and an increase in PAI-1 expression, most significant at 7 days of exposure. During hyperglycemia, because of the increased nutrient availability, much of the excess glucose is shunted into the hexosamine pathway. The end product of this pathway, UDP- $N$-acetylglucosamine, is the substrate for the glycosylation of important intracellular factors (McClain and Crook, 1996) including transcription factors. Accordingly, the expression of many genes including PAI-1 is increased, leading to the development of the microvascular complications of diabetes (Gabriely et al., 2002; Goldberg et al., 2002).

Disruption of mitochondrial respiratory function has been implicated as a key factor in the development of diabetic complications (Rolo and Palmeira, 2006). Furthermore, a large number of studies implicates reduction of transcription factors that lead to a balanced program of mitochondrial biogenesis has a causative factor for insulin resistance and diabetes (Rolo and Palmeira, 2006). Reduced expression of oxidative phosphorylation genes has been observed in type 2 diabetes (Mootha et al., 2003), accompanied by decreased expression of PGC- $1 \alpha$ in prediabetic and diabetic muscle (Patti et al., 2003). Insulin resistance is associated with decreased protein content of the ATP synthase $\beta$ subunit (Hojlund et al., 2003). High-fat diet, which leads to insulin resistance due to increased concentrations of free fatty acids, downregulates PGC- $1 \alpha$ mRNA and genes encoding proteins for complexes I, II, III, and IV (Sparks et al., 2005).

The relationship between ROS and these alterations in mitochondrial biogenesis is still unclear. Recently, it has been shown that hyperglycemic conditions are responsible for an increase in ROS production that is accompanied by increased fission or decreased fusion to fragment mitochondria (Yu et al., 2006), probably as a physiologic response to increased metabolic substrate availability. Our data clearly show that a decrease in mtDNA copy number occurs after prolonged exposure to high glucose (7 days in culture). These data suggest that the functional consequence of the alteration in mitochondrial biogenesis is a decrease in the cell respiratory capacity at 7 days in culture. Despite the increase in ROS, protein oxidation and PAI-1 expression, cell viability upon exposure to hyperglycemia was not different from control. TFAM is a key nuclearly encoded transcription factor, which translocates to mitochondria and activates mitochondrial transcription and mtDNA replication (Kelly and Scarpulla, 2004). TFB1M and TFB2M markedly enhance mtDNA transcription in the presence of TFAM and mitochondrial RNA polymerase. Previous studies have shown that in transgenic mice, over- expression of TFAM is sufficient to increase mtDNA copy number (Ekstrand et al., 2004). Also, in vitro, TFAM overexpression appears sufficient to induce mitochondrial transcription, but not mtDNA replication (Maniura-Weber et al., 2004). On the other hand, reduction of TFAM by RNA interference in HeLa cells or gene deletion in the mouse reduces mtDNA copy number (Ekstrand et al., 2004; Kanki et al., 2004). Thus TFAM is necessary for mtDNA replication and mitochondrial biogenesis. Although, in the present study, we did not evaluate any other factors responsible for mitochondrial biogenesis, we correlate the decrease in mtDNA copy number/cell with a decrease in TFAM after 7 days of exposure to hyperglycemia. Associated to these changes, is impairment in mitochondrial function and a decrease in MitoTracker Red staining (indicating a decrease in mitochondrial mass and/or a decrease in mitochondrial membrane potential) after 7 days of exposure to hyperglycemia, with an early increase in ROS generation, observed as early as $48 \mathrm{~h}$ of exposure to $30 \mathrm{mM}$ glucose. Our data indicate that chronic exposure to high glucose is responsible for a progressive alteration in gene expression, including a decrease in mitochondrial biogenesis. This further impairs oxidative metabolism and increases ROS production, establishing a vicious metabolic cycle that will lead to irreversible tissue damage in diabetes.

In conclusion, our findings indicate that modulation of mitochondrial biogenesis can be a therapeutic target to prevent a chronic disturbance of the metabolic status in diabetes.

\section{Acknowledgments}

We would like to acknowledge LaRae Peterson for fluorescence microscopy. This work was in part supported by HL 58016 and HL 72175 grants from National Institute of Health. C.M. Palmeira is recipient of a fellowship from Science and Technology Foundation (SFRH/BSAB/349/2003). A. P. Rolo is a recipient of fellowship from Science and Technology Foundation (SFRH/ BPD/26514/2006).

\section{References}

Berthiaume, J., Wallace, K.B., 2002. Perfluorooctanoate, perflourooctanesulfonate, and $\mathrm{N}$-ethyl perfluorooctanesulfonamido ethanol; peroxisome proliferation and mitochondrial biogenesis. Toxicol. Lett. 129, 23-32.

Bradford, M.M., 1976. A rapid and sensitive method for the quantitation of microgram quantities of protein utilizing the principle of protein-dye binding. Anal. Biochem. 72, 248-254.

Brownlee, M., 2001. Biochemistry and molecular cell biology of diabetic complications. Nature 414, 813-820.

Ekstrand, M.I., Falkenberg, M., Rantanen, A., Park, C.B., Gaspari, M., Hultenby, K., Rustin, P., Gustafsson, C.M., Larsson, N.G., 2004. Mitochondrial transcription factor A regulates mtDNA copy number in mammals. Hum. Mol. Genet. 13, 935-944.

Ferreira, F.M.L., Seiça, R., Santos, M.S., Palmeira, C.M., 1999. Age-related alterations in liver mitochondrial bioenergetics of diabetic Goto-Kakizaki rats. Acta Diabetol. 36, 173-177.

Ferreira, F.M., Moreno, A.J., Seiça, R., Santos, M.S., Palmeira, C.M., 2003. Diabetes and mitochondrial bioenergetics: alterations with age. J. Biochem. Mol. Toxicol. 17, 214-222.

Gabriely, I., Yang, X.M., Cases, J.A., Ma, X.H., Rossetti, L., Barzilai, N., 2002. Hyperglycemia induces PAI-1 gene expression in adipose tissue by 
activation of the hexosamine biosynthetic pathway. Atherosclerosis 160 , $115-122$.

Goldberg, H.J., Whiteside, C.I., Fantus, I.G., 2002. The hexosamine pathway regulates the plasminogen activator inhibitor-1 gene promoter and $\mathrm{Sp} 1$ transcriptional activation through protein kinase $\mathrm{C}^{\prime} \beta \mathrm{I}$ and $-^{\prime} \delta$. J. Biol. Chem. 277, 33833-33841.

Hofhaus, G., Shakeley, R.M., Attardi, G., 1996. Use of polarography to detect respiration defects in cell cultures. Methods Enzymol. 264, 476-483.

Hojlund, K., Wrzesinski, K., Larsen, P.M., Fey, S.J., Roepstorff, P., Handberg, A., Dela, F., Vinten, J., McCormack, J.G., Reynet, C., Beck-Nielsen, H., 2003. Proteome analysis reveals phosphorylation of ATP synthase betasubunit in human skeletal muscle and proteins with potential roles in type 2 diabetes. J. Biol. Chem. 278, 10436-10442.

Kanki, T., Ohgaki, K., Gaspari, M., Gustafsson, C.M., Fukuoh, A., Sasaki, N., Hamasaki, N., Kang, D., 2004. Architectural role of mitochondrial transcription factor A in maintenance of human mitochondrial DNA. Mol. Cell. Biol. 24, 9823-9834.

Kelly, D.P., Scarpulla, R.C., 2004. Transcriptional regulatory circuits controlling mitochondrial biogenesis and function. Genes Dev. 18, 357-368.

King, H., Aubert, R.E., Herman, W.H., 1998. Global burden of diabetes, 1995-2025: prevalence, numerical estimates, and projections. Diabetes Care 21, 1414-1431.

Levine, R.L., Williams, J.A., Stadtman, E.R., Shacter, E., 1994. Carbonyl assays for determination of oxidatively modified proteins. Methods Enzymol. 233, 346-357.

Maniura-Weber, K., Goffart, S., Garstka, H.I., Montoya, J., Wiesner, R.J., 2004. Transient overexpression of mitochondrial transcription factor A (TFAM) is sufficient to stimulate mitochondrial DNA transcription, but not sufficient to increase mtDNA copy number in cultured cells. Nucleic Acids Res. 32, 6015-6027.

McClain, D.A., Crook, E.D., 1996. Hexosamines and insulin resistance. Diabetes 45, 1003-1009.

Mootha, V.K., Lindgren, C.M., Eriksson, K.F., Subramanian, A., Sihag, S., Lehar, J., Puigserver, P., Carlsson, E., Ridderstrale, M., Laurila, E., Houstis, N., Daly, M.J., Patterson, N., Mesirov, J.P., Golub, T.R., Tamayo, P., Spiegelman, B., Lander, E.S., Hirschhorn, J.N., Altshuler, D., Groop, L.C., 2003. PGC-1alpha-responsive genes involved in oxidative phosphorylation are coordinately downregulated in human diabetes. Nat. Genet. 34, 267-273.

Nishikawa, T., Edelstein, D., Brownlee, M., 2000a. The missing link: a single unifying mechanism for diabetic complications. Kidney Int. 58, S26-S30.
Nishikawa, T., Edelstein, D., Du, X.L., Yamagishi, S.-I., Matsumura, T., Kaneda, Y., Yorek, M.A., Beebe, D., Oates, P.J., Hammes, H.-P., Giardino, I., Brownlee, M., 2000b. Normalizing mitochondrial superoxide production blocks three pathways of hyperglycaemic damage. Nature 404, 787-790.

Palmeira, C.M., Ferreira, F.M.L., Santos, D.L., Seiça, R., Suzuki, K.-I., Santos, M.S., 1999. Higher efficiency of the liver phosphorylative system in diabetic Goto-Kakizaki (GK) rats. FEBS Lett. 458, 103-106.

Patti, M.E., Butte, A.J., Crunkhorn, S., Cusi, K., Berria, R., Kashyap, S., Miyazaki, Y., Kohane, I., Costello, M., Saccone, R., Landaker, E.J., Goldfine, A.B., Mun, E., DeFronzo, R., Finlayson, J., Kahn, C.R., Mandarino, L.J., 2003. Coordinated reduction of genes of oxidative metabolism in humans with insulin resistance and diabetes: potential role of PGC1 and NRF1. Proc. Natl. Acad. Sci. U. S. A. 100, 8466-8471.

Puigserver, P., Spiegelman, B.M., 2003. Peroxisome proliferator-activated receptor-gamma coactivator 1 alpha (PGC-1 alpha): transcriptional coactivator and metabolic regulator. Endocr. Rev. 24, 78-90.

Robertson, R.P., 2004. Chronic oxidative stress as a central mechanism for glucose toxicity in pancreatic islet beta cells in diabetes. J. Biol. Chem. 279, 42351-42354.

Rolo, A.P., Palmeira, C.M., 2006. Diabetes and mitochondrial function: role of hyperglycemia and oxidative stress. Toxicol. Appl. Pharmacol. 212, $167-178$.

Rolo, A.P., Palmeira, C.M., Holy, J.M., Wallace, K.B., 2004. Role of mitochondrial dysfunction in combined bile acid-induced cytotoxicity: the switch between apoptosis and necrosis. Toxicol. Sci. 79, 196-204.

Sparks, L.M., Xie, H., Koza, R.A., Mynatt, R., Hulver, M.W., Bray, G.A., Smith, S.R, 2005. A high-fat diet coordinately downregulates genes required for mitochondrial oxidative phosphorylation in skeletal muscle. Diabetes 54, 1926-1933.

Strauss, W., 1998. Preparation of genomic DNA from mammalian tissue. In Ausubel, F., Brent, R., Kingston, R., Moore, D., Seidman, J., Smith, J., Struhl, K. (Eds.), Current Protocols in Molecular Biology, vol. 1. Wiley, USA, pp. 2.2.1-2.2.3.

Yu, T., Robotham, J.L., Yoon, Y., 2006. Increased production of reactive oxygen species in hyperglycemic conditions requires dynamic change of mitochondrial morphology. Proc. Natl. Acad. Sci. 103, 2653-2658.

Wu, Z., Puigserver, P., Andersson, U., Zhang, C., Adelmant, G., Mootha, V., Troy, A., Cinti, S., Lowell, B., Scarpulla, R.C., Spiegelman, B.M., 1999. Mechanisms controlling mitochondrial biogenesis and respiration through the thermogenic coactivator PGC-1. Cell 98, 115-124.

Zhou, S., Palmeira, C.M., Wallace, K.B., 2001. Doxorubicin-induced persistent oxidative stress to cardiac myocytes. Toxicol. Lett. 121, 151-157. 